\title{
Cell disassembly during apoptosis
}

\author{
Aaron Smith#, Michael AF Parkes#, Georgia K Atkin-Smith ${ }^{1}$, Rochelle Tixeira ${ }^{1}$, Ivan KH Poon ${ }^{\text {* }}$
}

\begin{abstract}
The disassembly of a dying cell into smaller fragments is a fundamental biological process during apoptosis. Recently, a number of distinct morphologic changes have been identified that could mediate the fragmentation of an apoptotic cell. Presented here is a figure that describes the progression of apoptotic cell disassembly.
\end{abstract}

Keywords: Apoptosis, cell biology, cell disassembly, microscopy

\section{Introduction}

Apoptosis, a common type of programmed cell death, occurs in most tissues as part of development and homeostasis as well as in pathogenic processes such as inflammation and infection. ${ }^{[1][2][3][4]}$ This fundamental biological process plays a key role in eliminating unwanted and potentially harmful cells. ${ }^{[2][3][4]}$ Apoptosis is most notably recognised by the morphological features that occur during its progression. ${ }^{[2][5]}$ An apoptotic cell can undergo a series of well-defined morphological steps (as described in detail below) to facilitate the fragmentation of the cell, leading to the formation of membrane-bound vesicles called apoptotic bodies ${ }^{[1][2][5][6]}$ (Figure 1). The process of generating apoptotic bodies during apoptosis is known as apoptotic cell disassembly. ${ }^{[5][6]}$ The functional significance of this process is still not well understood. Nevertheless, the formation of apoptotic bodies has been hypothesised to mediate intercellular communication and promote efficient clearance of apoptotic cells (a process known as efferocytosis). ${ }^{[3][5][7]}$

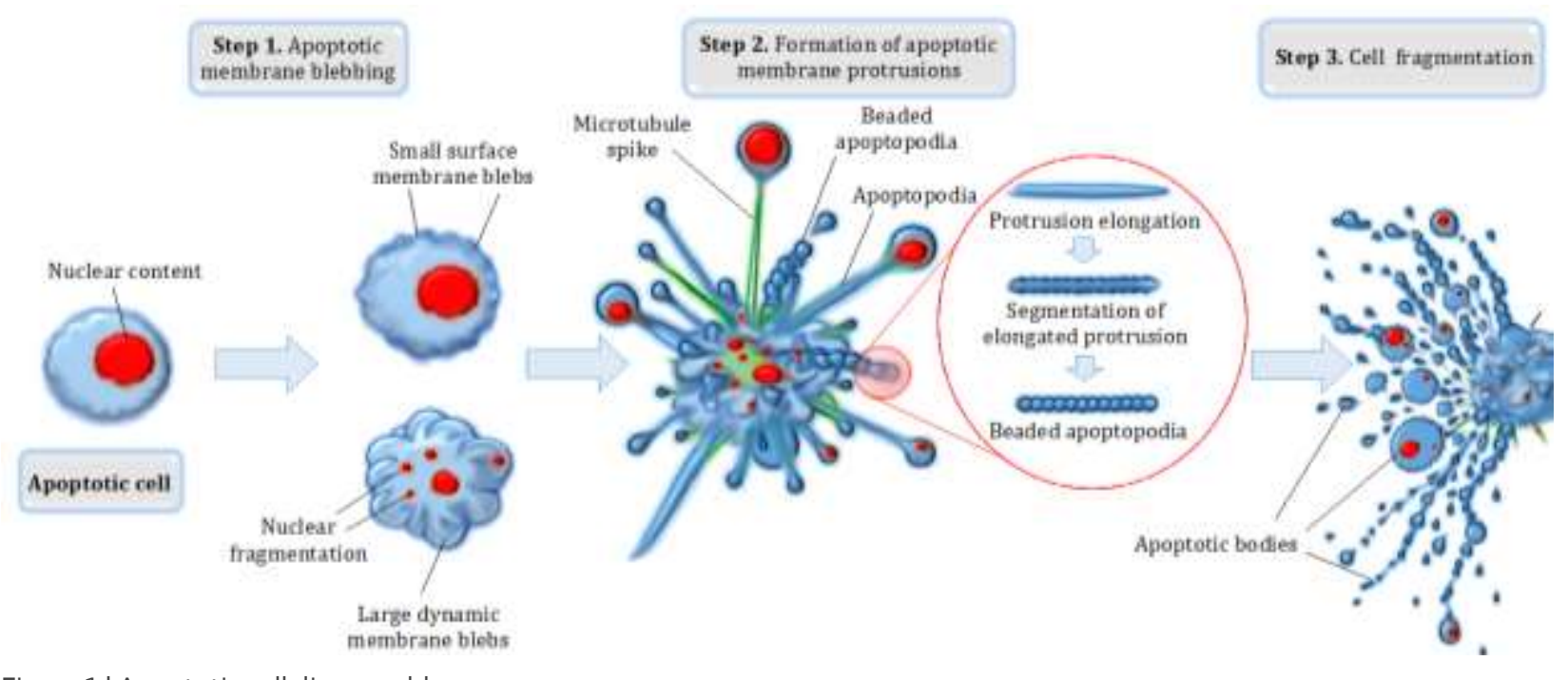

Figure 1 | Apoptotic cell disassembly.

\footnotetext{
${ }^{1}$ Department of Biochemistry and Genetics, La Trobe Institute for Molecular Science, La Trobe University, Melbourne, Victoria, Australia \#These authors contributed equally to this work.

*Author correspondence: i.poon@latrobe.edu.au Licensed under: CC-BY

Received og-06-2017; accepted 20-12-2017
}

1 of 3 | WikiJournal of Medicine 


\section{Step 1: Apoptotic membrane blebbing}

Upon extrinsic (receptor-activated) or intrinsic (mitochondrial-mediated) induction of apoptosis, ${ }^{\left[{ }^{8]}\right.}$ the dying cell can generate circular bulges or blebs on the cell surface, a process known as apoptotic membrane blebbing. ${ }^{[8]}$ Apoptotic membrane blebbing is considered the first step (Step 1) of apoptotic cell disassembly, which may appear as small surface membrane blebs at the early stages of apoptosis, or as large dynamic membrane blebs at later stages. ${ }^{[5][6]}$ The formation of large dynamic membrane blebs could facilitate the fragmentation of organelles such as the nucleus during the progression of apoptosis. ${ }^{[5][9]}$ Apoptotic membrane blebbing is regulated by a number of molecular factors, in particular caspase-activated ROCK1 (rho associated coiled-coil-containing protein kinase 1$).{ }^{[10][11]}$

\section{Step 2: formation of apoptotic membrane protrusions}

After apoptotic membrane blebbing, a cell can undergo further morphological changes to generate a variety of thin apoptotic membrane protrusions, including microtubule spikes, apoptopodia and beaded apoptopodia. $^{[12][13][14]}$ The formation of these apoptotic membrane protrusions are often cell type dependent and represents the second step (Step 2) of apoptotic cell disassembly ${ }^{[5][6]}$ (Figure 1). For example, microtubule spikes have been observed on apoptotic squamous epithelial cells. ${ }^{[12]}$ Mechanistically, the formation of microtubule spikes is dependent on microtubule polymerisation and establishment of the microtubule network. ${ }^{[12]}$ Microtubule spike formation has been proposed to facilitate the separation of membrane blebs, as well as the distribution of nuclear contents into membrane blebs. ${ }^{[12]}$ More recently, another type of less rigid and string-like apoptotic membrane protrusion, known as apoptopodia ('feet of death'), was identified on apoptotic T cells, thymocytes and fibroblasts. ${ }^{[13]}$ Like microtubule spikes, the formation of apoptopodia can mediate the separation of membrane blebs. ${ }^{[13]}$ Furthermore, apoptotic monocytes can generate another type of apoptotic membrane protrusion termed beaded apoptopodia that resembles 'beads-on-a-string'. ${ }^{[14]}$ Beaded apoptopodia formation begins with the generation and elongation of an apoptopodia-like protrusion, which then becomes segmented and appears as a string of beads. ${ }^{[14]}$ Currently, the only known molecular regulator of apoptopodia and beaded apoptopodia formation is the caspase-activated membrane channel PANX1 (pannexin 1). ${ }^{[13][14]}$

\section{Step 3: Cell fragmentation}

Lastly, the release of individual membrane-bound apoptotic bodies (generally considered as approximately 1 to 5 microns in diameter) represents the final step (Step 3) of apoptotic cell disassembly. ${ }^{[5][6]}$ Although the mechanism underpinning the final fragmentation process is not well defined, the disassociation of apoptotic bodies from different types of apoptotic membrane protrusion may require shear stress or perhaps even interaction with neighbouring cells. ${ }^{[5]}$ It should be noted that in addition to apoptotic bodies, membrane-bound vesicles that are smaller than $1 \mathrm{mi}-$ cron in diameter are also released during apoptosis. ${ }^{[15]}$

The release of apoptotic bodies from the dying cell has been proposed to facilitate communication between cells through proteins, microRNA and DNA present on/in apoptotic bodies. ${ }^{[3][5][16][17]}$ Apoptotic cell disassembly has also been proposed to aid cell clearance, as it could prove more efficient for a phagocytic cell to engulf smaller cell fragments (i.e. apoptotic bodies) rather than an apoptotic cell as a whole. ${ }^{[5][7]}$

\section{References}

1. Kerr JF, Wyllie AH, Currie AR (1972). "Apoptosis: a basic biological phenomenon with wide-ranging implications in tissue kinetics". Br. J. Cancer 26 (4): 239-57. doi:10.1038/bjc.1972.33. PMID 4561027. PMC 2008650.

2. Poon IK, Lucas CD, Rossi AG, Ravichandran KS (2014). "Apoptotic cell clearance: basic biology and therapeutic potential". Nat. Rev. Immunol. 14 (3): 166-80. doi:10.1038/nri3607. PMID 24481336. PMC 4040260.

3. Berda-Haddad $Y$, Robert S, Salers P, Zekraoui L, Farnarier C, Dinarello CA, Dignat-George F, Kaplanski G (2011). "Sterile inflammation of endothelial cell-derived apoptotic bodies is mediated by interleukin-1 $\alpha$ ". Proc. Natl. Acad. Sci. U.S.A. 108 (51): 20684-9. doi:10.1073/pnas.1116848108. PMID 22143786. PMC 3251090.

4. Muñoz LE, Lauber K, Schiller M, Manfredi AA, Herrmann M (2010). "The role of defective clearance of apoptotic cells in systemic autoimmunity". Nat. Rev. Rheumatol. 6 (5): 280-9. doi:10.1038/nrrheum.2010.46. PMID 20431553.

5. Atkin-Smith GK, Poon IK (2017). "Disassembly of the Dying: Mechanisms and Functions". Trends Cell Biol. 27 (2): 151-62. doi:10.1016/j.tcb.2016.08.011. PMID 27647018.

6. Tixeira R, Caruso S, Paone S, Baxter AA, Atkin-Smith GK, Hulett MD, Poon IK (2017). "Defining the morphologic features and products of cell disassembly during apoptosis". Apoptosis 22 (3): 475-7. doi:10.1007/s10495-017-1345-7. PMID 28102458.

7. Witasp E, Uthaisang W, Elenström-Magnusson C, Hanayama R, Tanaka M, Nagata S, Orrenius S, Fadeel B (2007). "Bridge over troubled water: milk fat globule epidermal growth factor 8 promotes human monocyte-derived macrophage clearance of non-blebbing phosphatidylserine-positive target cells". Cell Death Differ. 14 (5): 1063-5. doi:10.1038/sj.cdd.4402096. PMID 17256011.

8. Elmore S (2007). "Apoptosis: a review of programmed cell death". Toxicol. Pathol. 35 (4): 495-516. doi:10.1080/01926230701320337. PMID 17562483. PMC 2117903.

9. Wickman G, Julian L, Olson MF (2012). "How apoptotic cells aid in the removal of their own cold dead bodies". Cell Death Differ. 19 (5): 735-42. doi:10.1038/cdd.2012.25. PMID 22421963. PMC 3321633. 
10. Coleman ML, Sahai EA, Yeo M, Bosch M, Dewar A, Olson MF (2001). "Membrane blebbing during apoptosis results from caspase-mediated activation of ROCK I". Nat. Cell Biol. 3 (4): 339-45. doi:10.1038/35070009. PMID 11283606.

11. Sebbagh $M$, Renvoizé $C$, Hamelin J, Riché N, Bertoglio J, Bréard J (2001). "Caspase-3-mediated cleavage of ROCK I induces MLC phosphorylation and apoptotic membrane blebbing". Nat. Cell Biol. 3 (4): 346-52. doi:10.1038/35070019. PMID 11283607.

12. Moss DK, Betin VM, Malesinski SD, Lane JD (2006). "A novel role for microtubules in apoptotic chromatin dynamics and cellular fragmentation". J. Cell. Sci. 119 (Pt 11): 2362-74. doi:10.1242/jcs.02959. PMID 16723742. PMC 1592606.

13. Poon IK, Chiu YH, Armstrong AJ, Kinchen JM, Juncadella IJ, Bayliss DA, Ravichandran KS (2014). "Unexpected link between an antibiotic, pannexin channels and apoptosis". Nature 507 (7492): 329-34. doi:10.1038/nature13147. PMID 24646995. PMC 4078991.

14. Atkin-Smith GK, Tixeira R, Paone S, Mathivanan S, Collins C, Liem M, Goodall KJ, Ravichandran KS, Hulett MD, Poon IK (2015). "A novel mechanism of generating extracellular vesicles during apoptosis via a beads-on-a-string membrane structure". Nat. Commun. 6: 7439. doi:10.1038/ncomms8439. PMID 26074490. PMC 4490561.

15. Lynch C, Panagopoulou M, Gregory CD (2017). "Extracellular Vesicles Arising from Apoptotic Cells in Tumors: Roles in Cancer Pathogenesis and Potential Clinical Applications". Front. Immunol. 8: 1174. doi:10.3389/fimmu.2017.01174. PMID 29018443. PMC 5614926.

16. Holmgren L, Szeles A, Rajnavölgyi E, Folkman J, Klein G, Ernberg I, Falk KI (1999). "Horizontal transfer of DNA by the uptake of apoptotic bodies". Blood 93 (11): 3956-63. PMID 10339505.

17. Zernecke A, Bidzhekov K, Noels $H$, Shagdarsuren E, Gan L, Denecke B, Hristov M, Köppel T, Jahantigh MN, Lutgens E, Wang S, Olson EN, Schober A, Weber C (2009). "Delivery of microRNA-126 by apoptotic bodies induces CXCL12-dependent vascular protection". Sci. Signal. 2 (100): ra81. doi:10.1126/scisignal.2000610. PMID 19996457. 